Sensitivity of ecosystem goods and services projections of a forest landscape model to initialization data

\author{
Journal Article \\ Author(s): \\ Temperli, Christian; Zell, Jürgen; Bugmann, Harald; Elkin, Ché \\ Publication date: \\ 2013-08 \\ Permanent link: \\ https://doi.org/10.3929/ethz-b-000070502
}

Rights / license:

In Copyright - Non-Commercial Use Permitted

Originally published in:

Landscape Ecology 28(7), https://doi.org/10.1007/s10980-013-9882-0 


\title{
Sensitivity of ecosystem goods and services projections of a forest landscape model to initialization data
}

\author{
Christian Temperli · Jürgen Zell • \\ Harald Bugmann · Ché Elkin
}

Received: 19 November 2012/ Accepted: 19 March 2013/Published online: 4 April 2013

(C) Springer Science+Business Media Dordrecht 2013

\begin{abstract}
Projections of indicators of forest ecosystem goods and services (EGS) based on process-based landscape models are critical for adapting forest management to climate change. However, the scarcity of fine-grained, spatially explicit forest data means that initializing these models is both a challenge and a source of uncertainty. To test how different initialization approaches influence the simulation of forest dynamics and EGS indicators we initialized the forest landscape model LandClim with fine resolution empirical data, coarse empirical data, and simulation-derived data, and evaluated the results at three spatial scales (stand, management area and landscape). Simulations were performed for a spruce (Picea abies) dominated landscape in the Black Forest, Germany, under current climate and a climate change scenario. We found that long-term ( $>150$ years) projections are robust to initialization
\end{abstract}

Electronic supplementary material The online version of this article (doi:10.1007/s10980-013-9882-0) contains supplementary material, which is available to authorized users.

C. Temperli $(\bowtie) \cdot$ H. Bugmann · C. Elkin

Department of Environmental Systems Science, Forest

Ecology, Federal Institute of Technology, ETH Zurich,

Universitätstrasse 22, 8092 Zürich, Switzerland

e-mail: christian.temperli@env.ethz.ch

\section{J. Zell}

Forest Resources and Management, Swiss Federal Institute for Forest, Snow and Landscape Research WSL, Zürcherstrasse 111, 8903, Birmensdorf, Switzerland uncertainty. In contrast, shorter-term projections are sensitive to initialization uncertainty, with sensitivity increasing when EGS are assessed at smaller spatial scales, and when the EGS indicators depend on the spatial distribution of individual species. EGS dynamics are strongly influenced by interactions between the density, species composition, and age structure of initialized forests and simulated forest management. If EGS dynamics are strongly influenced by climate change, such as when climate change induces mortality in drought-sensitive species, some of the initialization uncertainty can be masked. We advocate for initializing landscape models with fine-grained data in applications that focus on spatial management problems in heterogeneous landscapes, and stress that the scale of analysis must be in accordance with the accuracy that is warranted by the initialization data.

Keywords Climate change - Forest inventory · Landscape model $\cdot$ Model initialization .

Simulation · Uncertainty

\section{Introduction}

Adapting forest management to future conditions requires knowledge on the combined influences of climate change and forest management on forest dynamics and ecosystem goods and services (EGS; Pretzsch et al. 2008; Heinimann 2010). To capture the complex non-linear impacts of climate on forests, such 
projections are often made using dynamic, climatesensitive models (Bugmann 2001; Schumacher et al. 2004; Radeloff et al. 2006). Forest landscape models aim to incorporate the impact of landscape-scale disturbances (He and Mladenoff 1999; Schumacher and Bugmann 2006), environmental heterogeneity (Elkin et al. 2012), and spatially explicit processes such as dispersal and landscape-level management (Radeloff et al. 2006; Temperli et al. 2012), so as to allow for a spatial evaluation of forest dynamics and EGS provisioning. However, the advantages of accurately representing environmental drivers and forest dynamics within a spatially explicit framework are often impaired by a lack of empirical data representing current forest state. Spatially explicit forest data are rarely available at a sufficient resolution and extent to initialize the models directly. Thus, forest landscape models are often initialized by simulating the current forest state based on assumptions on past climate and management. However, this type of initialization potentially degrades the link between simulation results and the real world, and may render projections unreliable from a forest manager's perspective (Schumacher et al. 2006; Steenberg et al. 2011; Sturtevant et al. 2012).

An alternative initialization approach that is more empirically grounded, and therefore more data intensive, is to represent initial forest conditions using a combination of empirical forest inventory data and geographically explicit forest planning maps. With this procedure information on the spatial distribution of forest types, or individual stands, can be complemented by tree species- and size class-specific stem numbers from forest inventory plots. While the use of spatially explicit empirical forest data has the potential to improve the realism of forest simulations, initializing dynamic models with this type of data may introduce separate challenges.

First, model assumptions regarding variables such as species composition, maximum tree biomass or stem numbers may be inconsistent with empirically derived initialization data. As a result, unrealistic abrupt shifts in response variables may result at the beginning of the simulation. In contrast, model assumptions will by definition conform to simulated initialization data that are derived from the same process model.

Second, empirical initialization data will always include measurement and sampling errors, which will contribute to uncertainty. In addition, extrapolating a comprehensive set of tree-level variables from limited empirical data will often have to be based on weakly substantiated assumptions. These uncertainties add to the parameterization and process uncertainties inherent to forest landscape models, with potentially large implications for the simulation results (Elkin et al. 2012). For example, uncertainty regarding the spatial distribution of tree species can influence projections of local abundance of target species, which can be very important when evaluating harvest and conservation goals (Fahrig 2003; Liang et al. 2011). Similarly, uncertainties regarding the initial size distribution of trees will influence simulated stand development and regeneration dynamics, which in turn will determine how forest stands respond to climate change (Buma and Wessman 2012). Therefore, care must be taken to ensure that uncertainty in the empirical data does not introduce a large bias in the simulation results.

The importance of these challenges will likely depend on the spatial and temporal scales at which forest property and EGS indicators are analyzed. While they may be decisive if analyses target small spatial scales and short timeframes, they may be negligible if results are analyzed at the landscape scale only (Xu et al. 2004). In addition, the influence of external drivers such as climate change may diminish the importance of these challenges, because it has the potential to cause large shifts in forest development trajectories that are independent of the initialized state (Temperli et al. 2012). However, it is unclear to what degree and over what timeframe climate change may dampen these initialization uncertainties.

Addressing these challenges is important to determine the robustness of forest projections, specifically when such projections are used to evaluate the resistance or resilience of forests in response to climate change and management decisions (Cordonnier et al. 2008; Kennedy and Wimberly 2009). Previous studies have assessed the sensitivity of forest model projections to uncertainty from scaling up plot data to the landscape scale (Miehle et al. 2006; Liang et al. 2011), from downscaling forest inventory data set (Xu et al. 2004; 2005) and from the formulation of tree-level processes (Deutschman et al. 1999; Elkin et al. 2012). These studies have generally found that the importance of such uncertainties is largest when the process-resolution of the model is small, and the spatial and ecological scale of projections is fine grained. However, we are unaware of any study that 
explicitly assessed the consequences of uncertainty in the initialization data for projections of EGS indicators, although this has been identified as a major limitation for forest landscape model applications (Shifley et al. 2008).

Here, we address this deficiency by assessing the effect of model initialization on forest projections by initializing a forest landscape simulation model (LandClim) with three representations of the current forest: fine- and coarse-grain empirical data, and simulated data. Starting from these three initialization states we projected forest development under current climate and a climate change scenario. We assessed the effect of the different initialization approaches on a range of EGS indicators, of which we analyzed the development through time and at three spatial scales (stand, management area and landscape). By doing so, we were able to quantify the sensitivity of the EGS indicators to the initialization data and climate change.

Specifically, we addressed the following questions: How sensitive are projections of forest EGS indicators to model initialization? Does model sensitivity change depending on the ecosystem characteristic considered, the scale at which forest responses are analyzed, and the time horizon of the projections? Does climate change dampen model initialization uncertainty? How do interactions between climate change and forest initialization state develop through time and influence projections of EGS indicators?

\section{Methods}

Study landscape

We simulated a $2 \times 10 \mathrm{~km}$ landscape at the western edge of the Northern Black Forest, Germany $\left(48^{\circ} 40^{\prime} \mathrm{N}\right.$, $8^{\circ} 13^{\prime} \mathrm{E}$ ). Elevation ranges from 250 to $1,050 \mathrm{~m}$ above sea level (a.s.1.) and climate is oceanic (Fig. 1; Table 1). At low elevations (<500 m a.s.1.), soil water holding capacity (Henne et al. 2011) is higher $(>15 \mathrm{~cm})$ than at higher elevations $(>500 \mathrm{~m}$ a.s.l.; $6-15 \mathrm{~cm}$; data provided by Forstliche Versuchsanstalt Baden-Württemberg). The potential natural vegetation would be a mixed European beech (Fagus silvatica L.) forest, with oaks (Quercus spp.) increasing in proportion towards lower elevations and silver fir (Abies alba Mill.) and Norway spruce (Picea abies (L.) Karst)

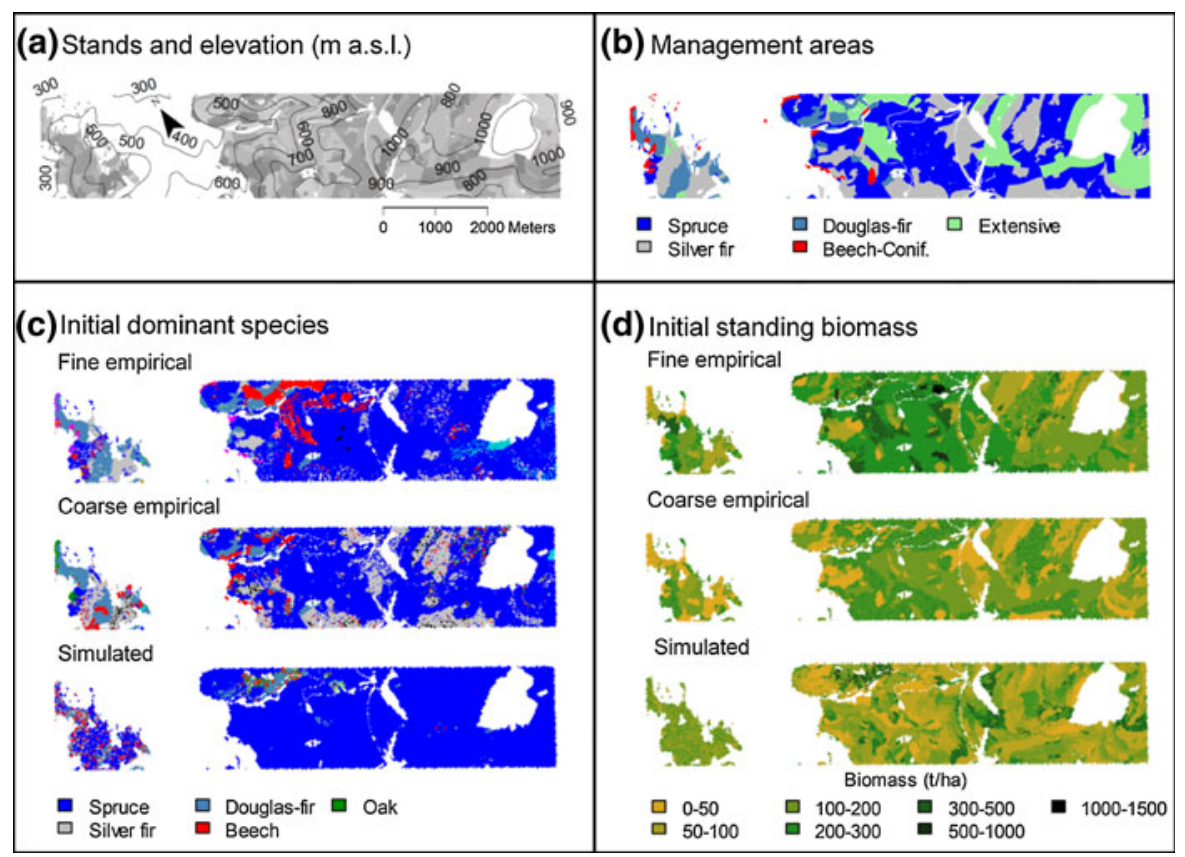

Fig. 1 Map of study area. Stand map and elevation (a); spatial allocation of uneven-aged mixed forest management regimes that favor varying dominant species (b); spatial distribution of dominant species (c) and biomass (d) represented by three initialization data sets (fine empirical, coarse empirical and simulated) 
Table 1 Current climate and a regional circulation model realization for the IPPC AR4 A1B emission scenario at $828 \mathrm{~m}$ a.s.1. in the Black Forest study landscape

\begin{tabular}{|c|c|c|c|c|c|c|}
\hline \multirow[b]{2}{*}{ Climate scenario } & \multicolumn{3}{|c|}{ Temperature $\left({ }^{\circ} \mathrm{C}\right)$} & \multicolumn{3}{|c|}{ Precipitation (mm) } \\
\hline & Annual & $\begin{array}{l}\text { Summer } \\
\text { (Apr-Sept) }\end{array}$ & $\begin{array}{l}\text { Winter } \\
\text { (Oct-Mar) }\end{array}$ & Annual & $\begin{array}{l}\text { Summer } \\
\text { (Apr-Sept) }\end{array}$ & $\begin{array}{l}\text { Winter } \\
\text { (Oct-Mar) }\end{array}$ \\
\hline Current climate (1950-2000) & 7.1 & 12.4 & 1.8 & 1,086 & 573 & 513 \\
\hline HCCPR (2081-2100) & 11.7 & 17.3 & 6.1 & 1,042 & 473 & 569 \\
\hline
\end{tabular}

The climate change scenario data are based on the HadRM3Q0/HadCM3Q0 model (Collins et al. 2006) by the Hadley Center for Climate Prediction and Research (HCCPR)

towards higher elevations (Müller et al. 1992). However, historic forest management that promoted Norway spruce has resulted in mixed Norway spruce/silver fir forests at lower elevations, with intermixed European beech and Douglas-fir (Pseudotsuga menziesii (Mirbel) Franco var. menziesii) mostly on dry sites. At higher elevations forests are a mosaic of mostly Norway spruce dominated stands of different age classes (map of forest stands provided by Forstliche Versuchsanstalt FVA Baden-Württemberg, Fig. 1a).

\section{LandClim model}

In LandClim forest landscape dynamics are modeled stochastically as a function of climate and soil properties on a grid of $25 \times 25 \mathrm{~m}$ cells. Within each cell a simplified forest gap model (Bugmann 2001) is used to simulate regeneration, growth and mortality of tree cohorts of the same species and size. Disturbance sub-models representing fire, wind, bark beetles and forest management are implemented at the landscape scale (Schumacher et al. 2004, 2006; Temperli et al. 2012). Simulated forests and forest processes have been proven to be consistent with empirical data in various applications (Schumacher et al. 2006; Colombaroli et al. 2010; Henne et al. 2011; Elkin et al. 2012; Temperli et al. 2012).

\section{Initialization data}

We used three different data sets to initialize LandClim (Fig. 1c, d, Table S1 in the supplementary material). The first is a simulated data set as is commonly used in forest landscape simulation applications (Schumacher et al. 2006; Steenberg et al. 2011; Sturtevant et al. 2012). We generated this data set by simulating the past management regimes (even-aged Norway spruce management at higher elevations and uneven-aged mixed forest management at lower elevations) under current climate into a pseudo-equilibrium (Temperli et al. 2012). While this approach approximates current species composition and stand structure reasonably well, the spatial distribution of the development stages (e.g., young, medium and mature stands) represents a single stochastic realization of the landscape at a single point in time, and therefore does not exactly correspond with the spatial pattern of the dbh distributions of the real forests.

Second, we initialized LandClim using coarsegrain empirical forest data from the second German National Forest Inventory (NFI; BMELV 2006) that were sampled in Baden-Württemberg on a $2 \times 2 \mathrm{~km}$ grid between 2001 and 2002. Sample trees were determined using the angle-count method. We used the dbh class- and species-specific stem number estimates from the sampling points located in the district of Rastatt $\left(740 \mathrm{~km}^{2}\right)$, in which our case study is located. These data were aggregated to represent 18 stand development types that are defined by current species composition, site properties and stand age. For each stand development type specific treatments and harvest thresholds are recommended by the state's forestry administration (MLR 1999). The forest management plan of our study landscape featured the same stand classification, such that stem number estimates for each stand could be allocated to specific stand development types, tree species and $4 \mathrm{~cm}$ diameter classes.

The third initialization data set was based on the fine-grained forest enterprise inventory (Betriebsinventur, BI, cf. Nothdurft et al. 2012) of BadenWürttemberg that was conducted over the last 15 years by private and municipal forest enterprises on $200 \times 200 \mathrm{~m}$ or finer grids. The BI used the same sampling protocol as the NFI with the exception that 
plot size was fixed. Even though the resolution of the BI was high, it was not sufficient to derive speciesspecific diameter distributions for individual stands (which ranged in size from $<0.1$ to 41 ha) directly by resampling from the plots located in our study landscape. We therefore used the BI plots available in whole Baden-Württemberg which included spatially explicit information on forest state regarding total volume, stand age, presence of understory and tree species' shares. As these descriptors of forest state were available for both the BI plots and each individual stand in our case study landscape we were able to estimate species-specific diameter distributions for each stand using the following procedure: First, we fitted left-truncated Weibull functions to the diameter distribution of each plot, thus yielding plot-specific shape and scale estimates. We then stratified the plots to stand development types, for each of which we built regression models that explained the Weibull parameters using the forest state descriptors described above. Using these statistical models we predicted stand- and species-specific diameter frequencies. This procedure allowed us to obtain species-specific diameter distributions that reflected stand-specific forest properties yielding the best available spatially explicit single stand estimates of the current forest states in this region.

Based on the stand-, species- and diameter classspecific stem number estimates from both the coarse and fine empirical data set we populated individual LandClim cells with tree cohorts, as follows. First, we obtained the stand-specific biomass stock by aggregating diameter and species frequencies after converting the midpoints of the $4 \mathrm{~cm}$ dbh classes to biomass using LandClim's allometric functions (Schumacher et al. 2004). Second, we sampled with replacement from the stand-specific species and diameter distributions until the biomass sum of the drawn trees reached the stand-specific biomass stock. This sampling procedure was replicated resulting in 15 independent stochastic realizations of landscape-scale initialization data sets that are based on the same diameter distributions at the stand level but differ in terms of the cell-specific allocation of trees.

Climate data

Monthly temperature and precipitation data were available from meteorological stations (1950-2000) and were used to simulate current climatic conditions. Future climate scenarios were based on Regional Climate Model data using the IPCC AR4 A1B emission scenario (2001-2100). The A1B realization results in an end-of-century increase of $4.6^{\circ} \mathrm{C}$ (Table 1), and represents an intermediate to strong climate change scenario (IPCC 2007). Climate data were interpolated to a 1 ha-grained elevation model (SRTM-3) using the procedures described in Thornton et al. (1997) by the Research Unit Landscape Dynamics of the Swiss Federal Institute for Forest, Snow and Landscape Research (WSL). We extended the climate time series to the year 2500 by assuming climate to stabilize after 2100 and by resampling the years 2080-2100, a commonly used approximation (Xu et al. 2009; Temperli et al. 2012) that serves to evaluate the relaxation time of the model, not to make predictions about future landscape states.

Forest management and simulation experiments

We simulated forest management as recommended by the local forestry administration (MLR 1999). Management regimes were spatially allocated according the mapped stand development types (Fig. 1b, MLR 1999, FVA). The study area included four management areas, where conversion management regimes are based on uneven-aged forestry that aim to develop climate change- and disturbance-resilient forest structure while promoting timber production and biodiversity objectives. These four management regimes differ in the dominant species they promote: mixed beechconifer, Norway spruce, silver fir and Douglas-fir, respectively. A fifth extensive management regime aims at promoting natural forest succession and is applied for stands originating from coppice management, usually on sites with poor soils (see supplemental Table S2 for details on the LandClim implementation of these management regimes).

Fifteen replicates of each of the three initialization and two climate scenario combinations were simulated. Each replicate was started using an individual stochastic realization of the initialization data.

\section{Indices of ecosystem goods and services}

Based on LandClim outputs we calculated indicators representing forest state and the capacity of forests to provide ecosystem goods services at three spatial 
scales: stand, management area and the entire landscape. We assessed the development of forest state by considering species-specific biomass.

Tree species diversity was assessed using Shannon entropy $(H$, Eq. 1$)$ at the stand, management area and landscape scale.

$H=-\sum_{i=1}^{s}\left(p_{i} \cdot \ln p_{i}\right)$

where $S$ is the number of species and $p_{i}$ is the stem number proportion per tree species. Species diversity measured by Shannon entropy has been used numerous times to assess the ecological value of forests (Lasch et al. 2002; Seidl et al. 2007); it accounts for the number of species and their relative abundance, both key factors determining resilience (Elmqvist et al. 2003).

Second, we calculated beta diversity as a measure for the spatial heterogeneity of the study landscape. Heterogeneous landscapes support high numbers of habitats and thus more species (Brin et al. 2009; Paillet et al. 2010; Hernández-Stefanoni et al. 2011). Following Jost (2007) we calculated beta diversity $\left(H_{\beta}\right)$ as the difference between gamma diversity $\left(H_{\gamma}\right)$, i.e. Shannon diversity of the whole landscape, and alpha diversity $\left(H_{\alpha}\right)$, i.e. mean Shannon diversity across the individual cells (Eq. 2).

$H_{\beta}=H_{\gamma}-H_{\alpha}$

Third, we measured the diversity of tree diameters as an index of stand structural diversity using Shannon entropy (Eq. 1) with $S$ representing the number of $4 \mathrm{~cm}$ bins of tree diameters at breast height (dbh) and $p_{i}$ the proportion of stems per dbh bin. This index accounts for the importance of stand structural diversity in the habitat requirements of a wide range of keystone species (McElhinny et al. 2005).

For timber production, we used the summarized harvested and thinned biomass, which includes leaves and branches.

\section{Impact of the initialization data at different spatial scales}

We assessed the sensitivity of the development of forest and EGS indicators by calculating differences between the three differently initialized simulations. To quantify the difference between species compositions we used Euclidian distance as a distance measure. Hence, the Euclidian distance between two species compositions is the root of the sum of the squared differences between the biomass estimates of individual tree species. We calculated differences at 10 -year time steps. To evaluate whether the impact of the initialization data set is scale- and/or climatedependent we conducted this analysis at the stand, management area and landscape scale by calculating mean differences at the respective scale for simulations under current climate and under climate change.

\section{Relative importance of initialization data and climate change}

To evaluate the relative importance of the initialization data versus climate change we quantified the effect of initialization and climate change on EGS indicators. We used the percent difference $(\theta)$ between the mean of 15 replicate EGS responses of reference simulations $\left(\mu_{\mathrm{R}}\right.$ : simulations under current climate and initialized with fine or coarse empirical data) and the mean EGS response for each of the six simulation treatments $\left(\mu_{\mathrm{T}}\right.$ : three initialization data sets by two climate scenarios) as our effect measure. This analysis considered EGS measurements at the landscape scale. To evaluate the temporal development of the initialization and climate change effect we calculated $\theta$ for each simulated decade i (Eq. 3).

$\theta_{\mathrm{i}}=\frac{\mu_{\mathrm{T}, \mathrm{i}}-\mu_{\mathrm{R}, \mathrm{i}}}{\mu_{\mathrm{R}, \mathrm{i}}} \times 100$

where $\mu_{\mathrm{R}, \mathrm{i}}$ is the value from the reference simulation and $\mu_{\mathrm{Ti}}$ is the value from corresponding simulation treatment during time period $i$.

\section{Results}

Development of species-specific biomass

No abrupt changes in biomass between initialization and the first simulation decade were observed with any of the three initialization data sets (Fig. 2). In all simulations species biomass, predominantly Norway spruce, increased and peaked after the first two to five decades. At this time the number of trees that reached the recommended harvesting thresholds (MLR 1999) was large enough that harvesting prevented a further biomass increase. 
Fig. 2 Development of species biomass in simulations initialized with fine empirical, coarse empirical and simulated data (in rows), under current climate and climate change (in columns)

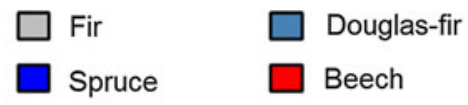

Current climate
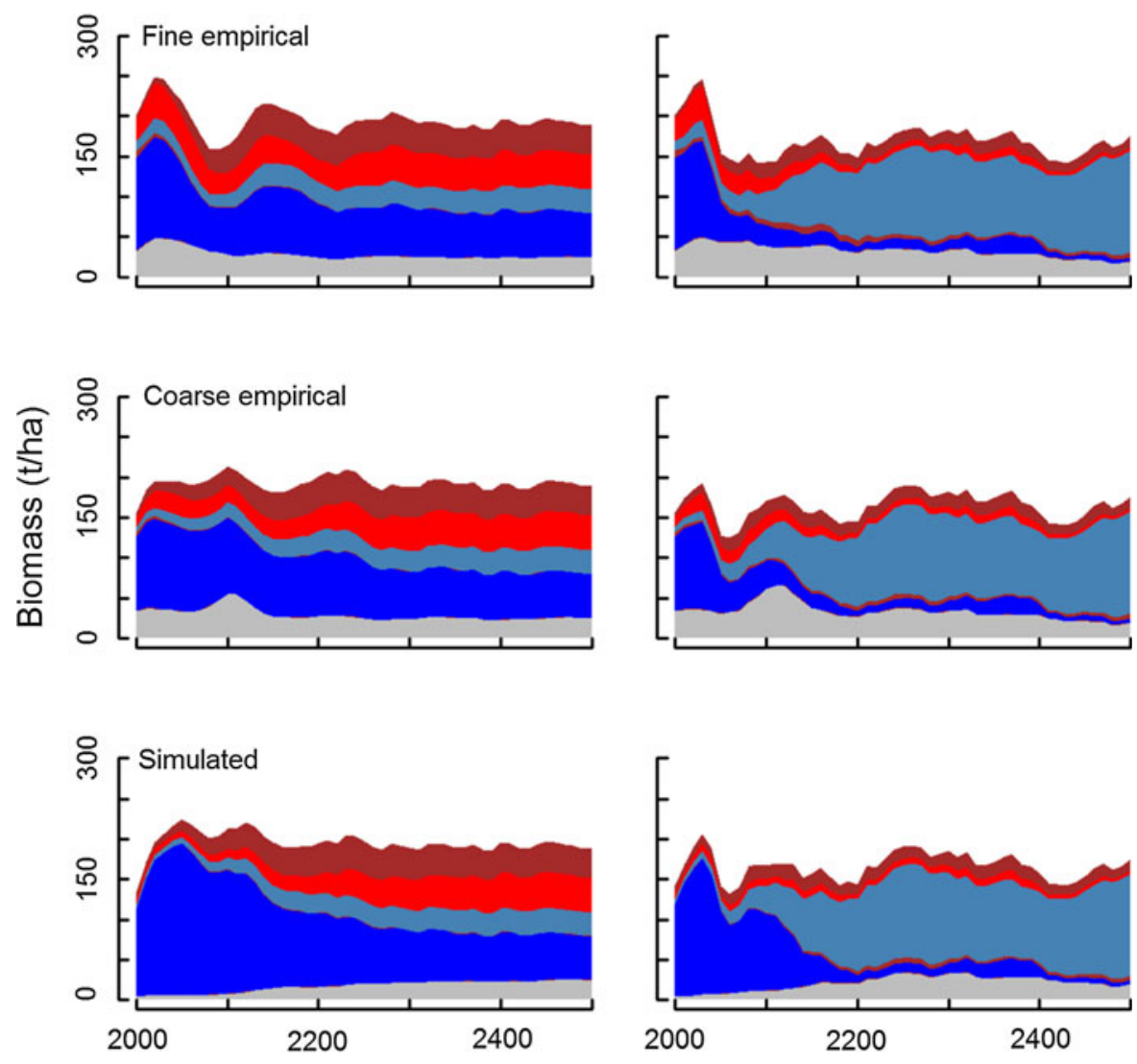

Irrespective of the initialization data forest biomass and species composition converged to the same climate- and management-driven equilibrium in the long term ( $>300$ years). Thereby the decrease in Norway spruce biomass and the increase of the biomass and diversity of deciduous tree species under current climate reflects the discrepancy between the current species composition and the implemented management targets (MLR 1999). The species composition simulated in the long term differs strongly between climate scenarios, with more droughtadapted tree species (mainly Douglas-fir) dominating under climate change.

On a shorter time scale ( $<300$ years) species composition fluctuated due to interactions between initialized stand structure and species composition on the one hand and the implemented management regimes on the other hand. Predominantly the biomass development of Norway spruce was affected by these interactions. Under current climate, and initialized with fine empirical data, simulated Norway spruce biomass increased until 2030 and then decreased drastically until 2100. At 2100 Norway spruce biomass increased again and settled at an equilibrium of ca. $50 \mathrm{t} / \mathrm{ha}$ after 2200 . Initialization with the coarse empirical data resulted in less pronounced fluctuations that were driven primarily by changes in silver fir. In simulations initialized with simulated data, Norway spruce biomass increased until reaching harvestable sizes in ca. 2050 and then decreased steadily to equilibrium, which was reached at about 2300 .

Irrespective of the different initialization states climate change had a large impact on projected species composition. Norway spruce started to die back 
towards to end of the 21st century, while Douglas-fir and other more drought-adapted species such as silver fir became increasingly dominant. In contrast to initialization with empirical data, when experiments were initialized with simulation data the consequence was a large amount of Norway spruce biomass persisting for another ca. 100 years after the initial dieback between ca. 2060 and 2100 .

Ecosystem goods and services

Differences in forest development due to initialization resulted in different dynamics in EGS indicators. All pairwise comparisons exhibited large differences in EGS indicator response for ca. 30-100 years, after which EGS indicators slowly converged. After 300 years differences in EGS indicators due to initialization were very small (Fig. 3). The sensitivity of EGS indicators to initialization differences was generally larger when assessed at a smaller spatial grain. Differences were larger between simulations initialized with empirical and simulated data than between simulations initialized with the two empirical data sets, with the largest differences occurring between simulations initialized with the fine empirical and the simulated data. Total forest biomass and stand structural diversity were relatively robust to initialization and climate scenarios. Species diversity and beta diversity were intermediately sensitive to initialization and relatively robust towards climate change, while Norway spruce biomass was highly sensitive to both initialization and climate change. Timber production was intermediately sensitive to both initialization and climate. Comparisons between climate change scenarios (Fig. 3 vs. 4) revealed that under climate change the initialization differences were smaller in amplitude and decreased sooner than under current climate.

Relative importance of initialization and climate change

The effect of the initialization data on all EGS indices decreased over time, as measured by the relative differences between differently initialized simulations; and by ca. 300 years the differences were eliminated. Relative to simulations under current climate, EGS indicators under climate change generally decreased with time (Fig. 5). This suggests that the lagged effects of initialization are important for a substantial amount of time, i.e. during the first ca. 150 years of projections of EGS indicators, whereas climate change becomes more influential in long-term ( $>150$ years) projections of EGS indicators. The size of both the initialization and the climate change effect varied greatly between EGS indicators.

Norway spruce biomass was most sensitive to initialization and climate change. The initialization effect peaked in 2090 (177\% more Norway spruce biomass) in the fine empirical and the simulated initialization comparison. The initialization effects on total biomass and Norway spruce biomass were similar, with the differences in Norway spruce biomass primarily driving the differences in total biomass.

The comparison of empirically initialized simulations with those initialized by simulated data revealed that species diversity and beta diversity are strongly ( $>-76$ and $>-88 \%$, respectively) affected by the initialization method during the first 150 years of the simulation.

The initialization method and climate change have a relatively low impact on stand structural diversity. The comparatively small effect of initialization during the first 70 years $(>-34 \%)$ reflect differences in when harvests were conducted: following simulated harvests of large Norway spruce trees (also reflected by a sharp drop in spruce biomass, Fig. 2), tree size diversity was abruptly lower at the landscape scale. The fluctuating initialization and climate change effects on timber provision result from differences in harvest timings between simulation runs.

\section{Discussion}

Sensitivity of forest properties

The empirically initialized simulations did not exhibit strong fluctuations of species-specific biomass during the first simulated decades, indicating that the initialization data were compatible with the intrinsic processes and assumptions that the model is based upon. Forest inventory data and vegetation maps are frequently used to initialize coarse-grained landscape models that depict forest attributes as presence/ absence of vegetation types or species-age cohorts 
Fine emp.-Coarse emp.

Species biomass composition
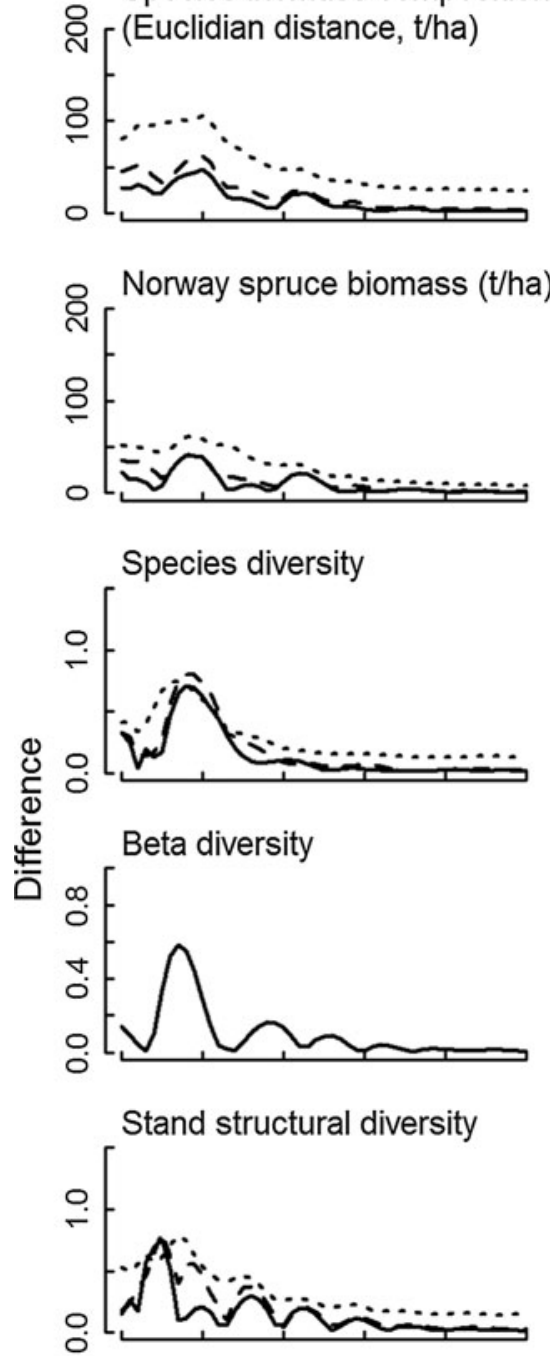

Timber (t/ha)

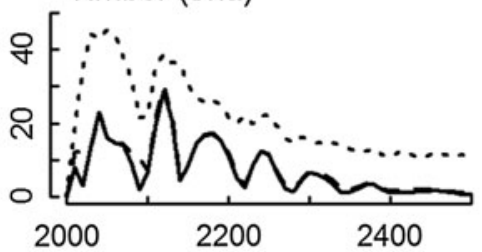

Fine emp.-Simulated

Coarse emp.-Simulated
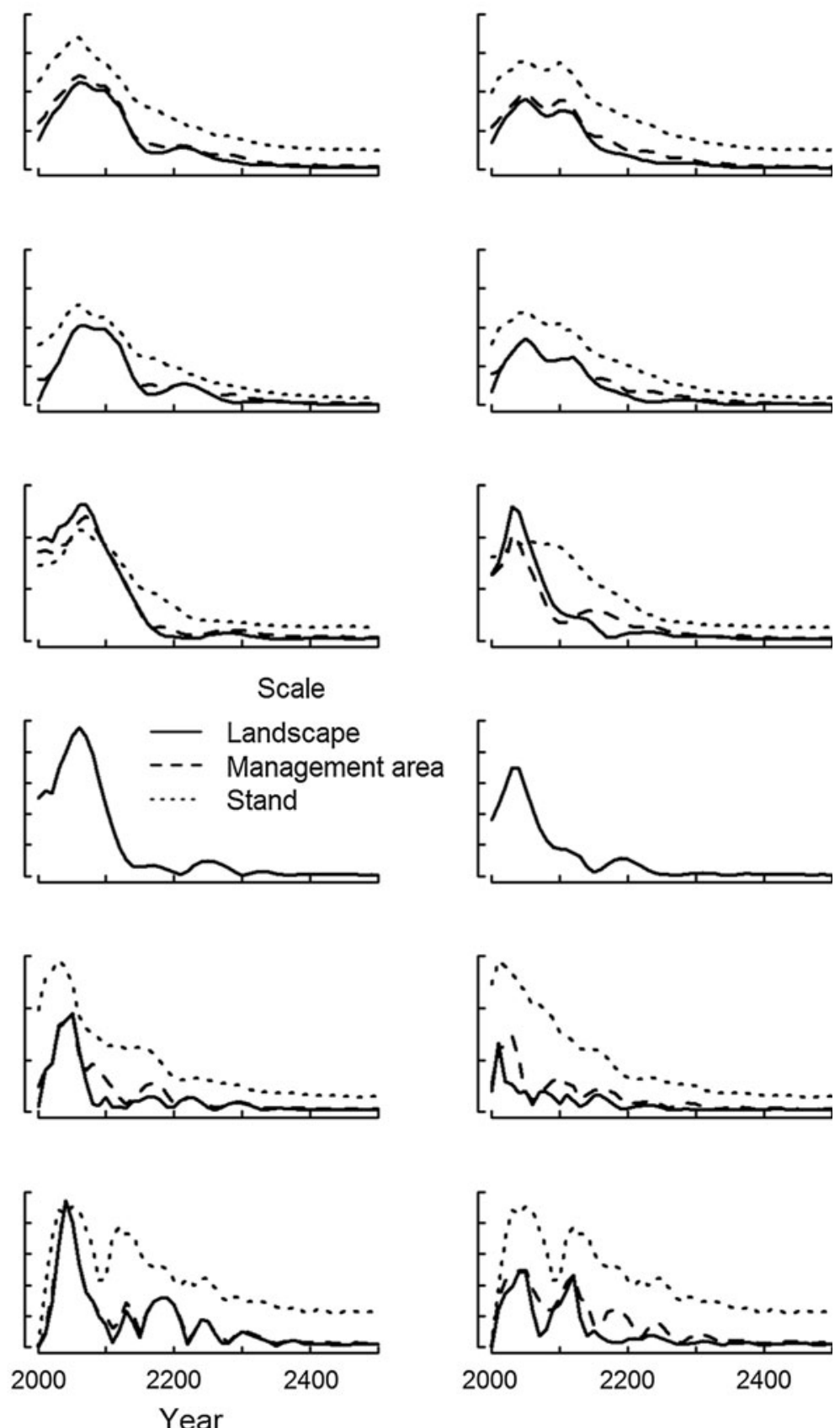

Fig. 3 Differences in ecosystem goods service indicators under current climate (in rows: species composition [Euclidian distance], Norway spruce biomass, species diversity, betadiversity, stand structural diversity, and timber production) between simulations initialized with different initialization data sets (in columns): fine empirical versus coarse empirical, fine empirical versus simulated and coarse empirical versus simulated data assessed at the stand, the management area and the landscape scale 


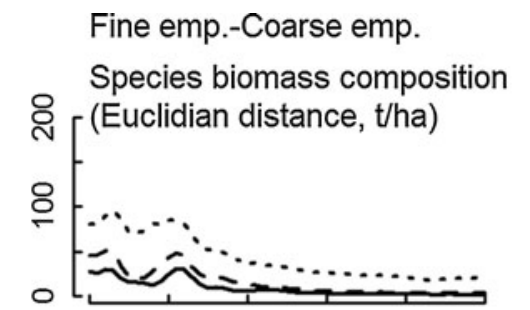

Fine emp.-Simulated

Coarse emp.-Simulated
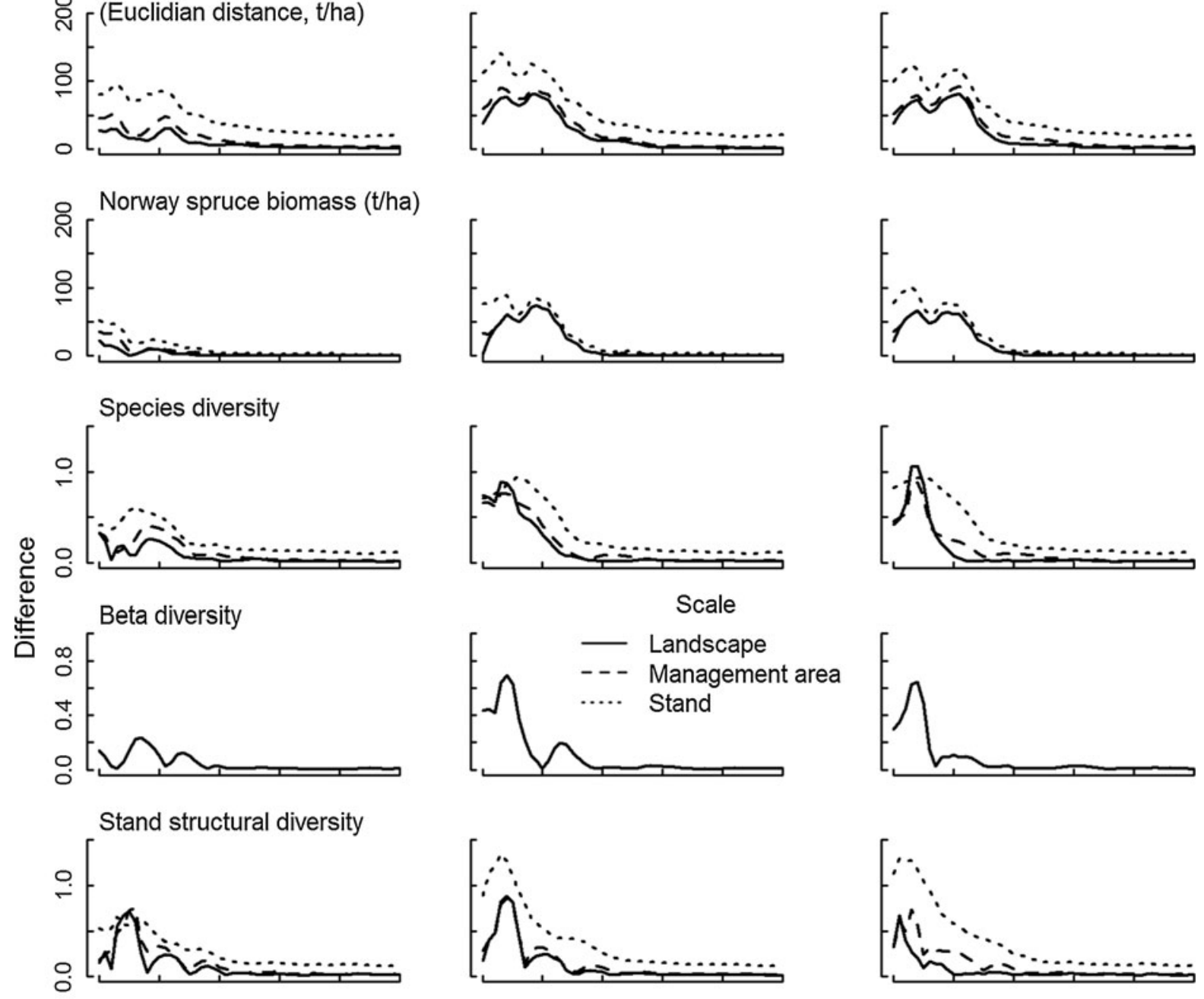

Timber (t/ha)
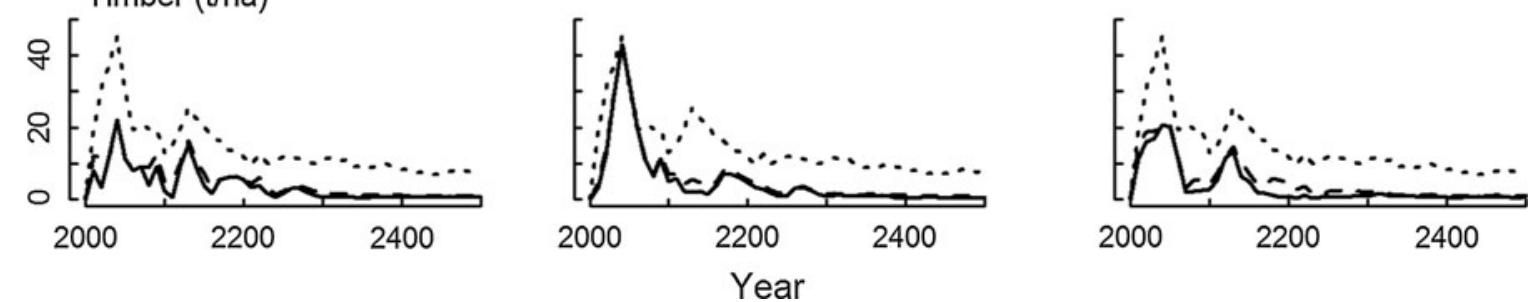

Fig. 4 Differences in ecosystem goods service indicators under climate change. See Fig. 3 caption for details

(He and Mladenoff 1999; Chew et al. 2004). Our work demonstrates that using fine-grained empirical initialization data offers the potential for landscape models such as LandClim (Schumacher et al. 2004) to produce more realistic simulations that explicitly track speciesspecific tree size and density distributions.
The type of data that the model was initialized with affected simulated dynamics in forest properties and EGS indicators as a result of cascading interactions between the initialized forest state and the management regimes. The different spatial resolutions of the coarse and fine forest inventory data, and the different 


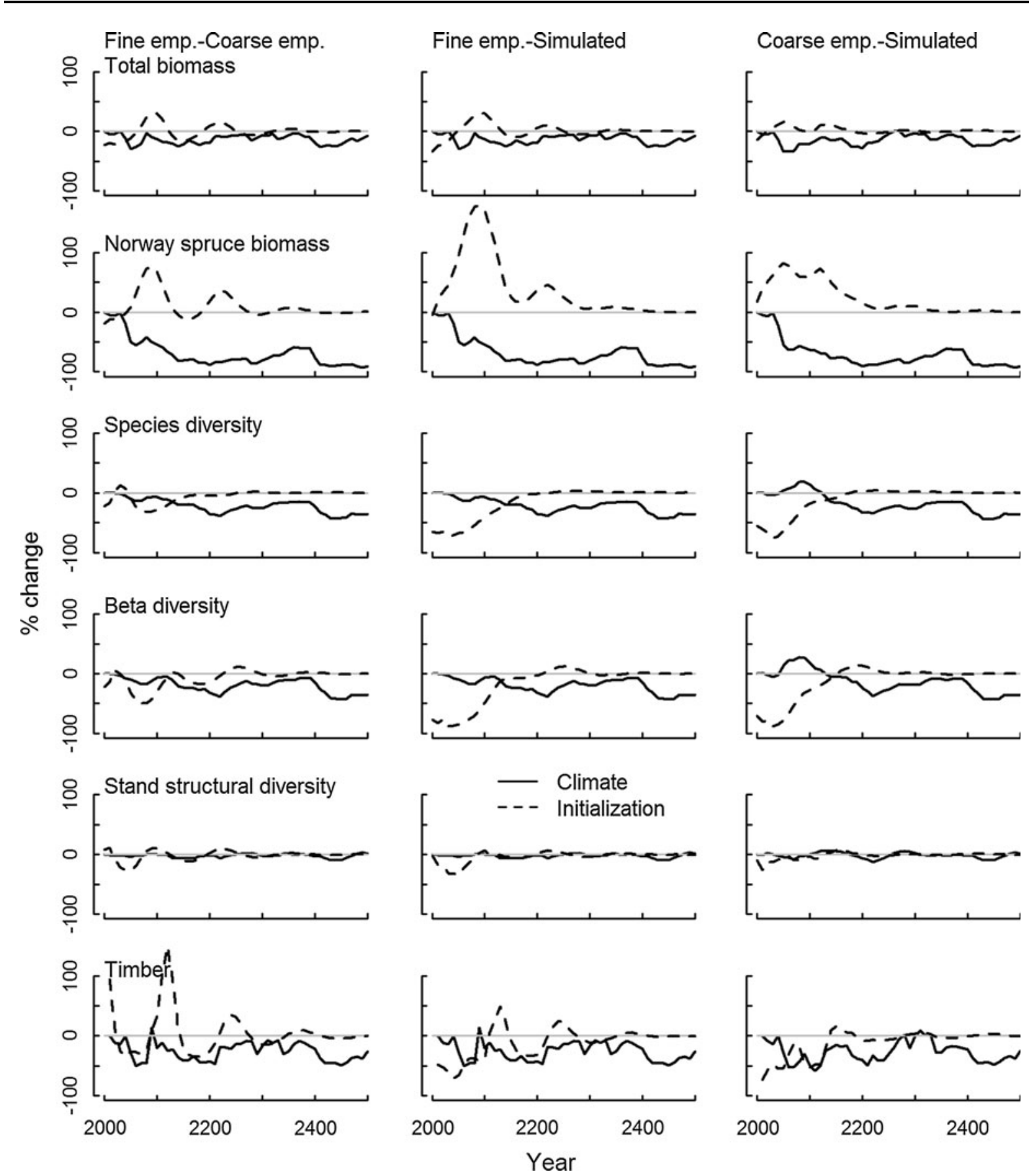

Fig. 5 Effect of initialization data and the effect of climate change on forest state and ecosystem goods and service indices (in rows; total biomass, Norway spruce biomass, species diversity, beta diversity, stand structural diversity and timber production). Effects were calculated each decade as the

approaches used to derive the initial species and tree size distributions, resulted in differences in tree size and species composition patterns among the percentage difference between a reference simulation and two alternatives that included current climate but different initialization data set versus climate change and the same initialization data. In columns the effects for all three combinations of initialization data sets are shown

initialization data sets (supplemental Table S1). This led to differences in harvest timing, which was based on dbh thresholds, which ultimately resulted in 
differences in simulated forest development. These differences were most apparent in projections of forest property and EGS indicators over the short$(<30$ years) to intermediate-term $(<100$ years), which are the timeframes most relevant to management decisions and policy making.

Norway spruce is the most abundant and heavily managed species in the case study, such that differences in the initialized age structure of this species had a large impact on projected forest dynamics. With the fine empirical data many old and even-aged Norway spruce stands were initially represented on the landscape (14\% of spruce trees $>40 \mathrm{~cm} \mathrm{dbh}$ ), which resulted in a large number of Norway spruce being projected to reach the harvesting threshold $(>60 \mathrm{~cm}$ $\mathrm{dbh}$ ) between 2040 and 2100. In contrast, when using the coarse empirical and the simulated initialization data set, the distribution of young and old stands was much more even (4 and $3 \%$ of spruce trees $>40 \mathrm{~cm}$ dbh, respectively, see supplemental Table S1). As a result, spruce trees reached the harvesting threshold over a longer time period and spruce harvest was more continuous.

Sensitivity of ecosystem goods and services

Projections of EGS indicators from the three initialization states diverged most in the medium term (2030-2100) and converged to management- and climate-driven equilibria in the long term. Note that these equilibria reflect the future forest state as a function of the implemented management and climate scenarios and that a formal validation of such future states is not possible. However, comparisons of LandClim simulation results and paleoecological records have shown that LandClim well approximates forest states under various climatic conditions (Colombaroli et al. 2010; Henne et al. 2011). The differences in the sensitivity to initialization and climate change between EGS indicators reflected the degree to which EGS indicators take into account the composition and spatial distribution of individual species, such as Norway spruce, hence the low sensitivity of total forest biomass and stand structural diversity versus the high sensitivity of species and beta diversity.

Simulated initialization data contained relatively low inter- and intra-cell heterogeneity, which resulted in low estimates of species diversity and beta diversity compared to both empirical data sets (supplemental Table S1). The homogeneity of the simulated initialization data reflects the simplistic spatial allocation of historic management regimes used to approximate the current forest state (Temperli et al. 2012). Simulating more nuanced historical management at a finer spatial grain would have produced more heterogeneous forest properties. However, comparable to the paucity of fine-grained initialization data, fine-grained forest maps and associated management records are often difficult or impossible to obtain.

Species diversity and stand heterogeneity may have been overestimated in the empirical data sets as a result of the pooling of inventory data to derive the stand development type- (coarse empirical data) and stand-specific (fine empirical data) distributions of species and diameter classes. This sensitivity of species diversity has considerable implications, e.g. for the application of landscape models to project wildlife habitats and forest resilience (e.g., Kennedy and Wimberly 2009). As species diversity and heterogeneity are key components of these EGS, great care is required in representing current forest states accurately across spatial scales (Papaik et al. 2010).

\section{Relative importance of climate change}

Climate change may force a forest towards a new equilibrium state (Bugmann 1997; Kirilenko and Sedjo 2007; Hanewinkel et al. 2010; Ravenscroft et al. 2010), such that the uncertainty due to initialization may be partially masked. In our case study region, the difference between current and future forest state under climate change was much greater than the divergence between the three initialization types (Fig. 2). However, the importance of climate change in our case study is contingent on the high initial abundance of drought-sensitive Norway spruce (Schlyter et al. 2006; Hanewinkel et al. 2010), the dieback of which caused a relatively fast convergence to the climate-driven equilibrium. The relative importance of climate change would likely have been smaller if the initial forest state had been more drought-resistant (Fischer et al. 2006).

Importance of spatial and temporal scale

Our finding that uncertainty in the spatial distribution of forest properties has a larger impact on EGS 
projections at smaller spatial scales is in agreement with earlier research by $\mathrm{Xu}$ et al. $(2004,2005)$ who quantified cell- and landscape-scale uncertainty that results from populating cells from a given forest inventory data set.

Our longer-term projections were robust to initialization, while those shorter than ca. 150 years were sensitive. This shorter time horizon covers the rotation lengths for most tree species, and this is the time scale that is most relevant for the planning of adaptive forest management (Briner et al. 2012; Temperli et al. 2012; Yousefpour et al. 2012). We expect simulations that include intensive management to promote a specific species composition, such as conversion to more drought-adapted species, to be less sensitive to initialization than simulations of (near-) natural forest dynamics.

Generating robust projections of forest properties and EGS

Forward-looking forest simulations are conducted for a variety of reasons, including evaluating the impact of climate change on forest dynamics (Lasch et al. 2002; Schumacher et al. 2006; Xu et al. 2009), testing alternative management options (Bolte et al. 2009; Temperli et al. 2012), and evaluating the risk of largescale disturbances (Uriarte et al. 2009; Seidl et al. 2011). The objective of a study, and the spatial and temporal grain at which the output needs to be evaluated, will strongly influence the type of initialization data that are suitable.

Obtaining fine-grained spatially explicit forest data is costly, but allows for the most accurate initialization with respect to the spatial distribution of species composition and stand structure. If available, such data sets should be employed for projections of EGS indicators that take into account fine-scale heterogeneity in species and tree size distributions, particularly for case studies that are structured at fine spatial scales due to past management activities or environmental heterogeneity. Coarse forest data from National Forest Inventories or vegetation maps have the advantages of being widely available and publicly accessible. However, forest inventory data are usually collected on coarse $(>1 \mathrm{~km})$ grids and vegetation maps do not contain information on stand structure, such that these data need to be further downscaled for many applications of dynamic landscape models. This downscaling introduces uncertainty with respect to fine-scale forest heterogeneity (Keane et al. 1999; Syphard et al. 2007; Shifley et al. 2008). Such data may be appropriate for the initialization of relatively homogeneous forest landscapes, given that their characteristics can be sufficiently captured.

Initialization with simulated data is the least dataand labor-intensive alternative, and in the absence of spatially explicit empirical data the only choice. However, to approximate the initial forest, first the external drivers of past forest dynamics (climate, management and disturbance regimes) must be known, and second written or mapped descriptions of current forests need to be available to verify simulated current forest states. While this approach is convenient to approximate unmanaged forests with model-derived potential natural vegetation (Waldron et al. 2007), the reconstruction of highly structured forest landscapes is afflicted with large uncertainties, because past disturbances and management activities, and their spatial distribution, are rarely documented adequately (Sturtevant et al. 2012; Temperli et al. 2012).

\section{Conclusions}

While the impact of uncertainty in model parameterization, landscape constraints, climate input and future forest management on forest landscape projections has been quantified previously (Cary et al. 2006; Schumacher and Bugmann 2006; Xu et al. 2009; Elkin et al. 2012; Temperli et al. 2012), this is the first study that focuses on how initialization uncertainty influences projections of a range of forest and EGS indicators under climate change and across spatial and temporal scales. Our results demonstrate that long-term, landscape scale projections of forest EGS indicators by process-based landscape models are rather robust to uncertainty in initialization data, particularly if strong climate and/or management drivers are simulated over the long term. In contrast, shorter-term ( $<150$ years) projections are sensitive to initialization uncertainty, with sensitivity increasing when EGS are assessed at smaller spatial scales and take into account the composition and spatial distribution of tree species.

In the presence of such initialization uncertainties, the assumptions and procedures to represent an initial forest state need to be transparent such that projections 
of EGS indicators can be conceived in relation to the initialized forest state, independent of its congruence with real forest properties. In general, outputs of process-based forest landscape models should not be interpreted for specific locations; they are not and cannot be forecasts of the fate of individual trees. Instead, process-based forest landscape models are most useful when they are used to reveal the mechanisms behind landscape-scale forest and EGS dynamics in response to initial forest states, spatial and temporal variation in environmental drivers, forest management and disturbances.

However, initialization data that sufficiently reflect the diversity and complexity of forest landscape conditions will be crucial for applications of processbased landscape models in case studies that are structured at small spatial scales. This is even more important when interactions between forest dynamics, disturbances and management activities are evaluated with respect to fine-scale EGS provision within the 100-year time frame for which climate change data are available. Thus, initialization uncertainty needs to be minimized to the point where accuracy in the initialization data can be warranted at the scale of analysis.

Acknowledgments We thank Dirk Schmatz (WSL) for providing downscaled climate scenario data. C. T. and J. Z. were funded by MOTIVE, a project within the European commission's 7th framework program (Grant agreement no. 226544)

\section{References}

BMELV (2006) Survey instructions for the 2nd National Forest Inventory. 2nd corrected translation, February 2006, of the 2nd corrected and revised reprint, May 2001. Available from the Federal Ministry of Food, Agriculture 550 and Consumer Protection, Berlin

Bolte A, Ammer C, Lof M, Madsen P, Nabuurs GJ, Schall P, Spathelf P, Rock J (2009) Adaptive forest management in central Europe: climate change impacts, strategies and integrative concept. Scand J For Res 24:473-482

Brin A, Brustel H, Jactel H (2009) Species variables or environmental variables as indicators of forest biodiversity: a case study using saproxylic beetles in Maritime pine plantations. Ann For Sci 66:306-306

Briner S, Elkin C, Huber R, Grêt-Regamey A (2012) Assessing the impacts of economic and climate changes on land-use in mountain regions: a spatial dynamic modeling approach. Agric Ecosyst Environ 149:50-63

Bugmann H (1997) Sensitivity of forests in the European Alps to future climatic change. Clim Res 8:35-44
Bugmann H (2001) A review of forest gap models. Clim Change 51:259-305

Buma B, Wessman CA (2012) Differential species responses to compounded perturbations and implications for landscape heterogeneity and resilience. For Ecol Manag 266:25-33

Cary G, Keane R, Gardner R, Lavorel S, Flannigan MD, Davies ID, Li C, Lenihan JM, Rupp TS, Mouillot F (2006) Comparison of the sensitivity of landscape-fire-succession models to variation in terrain, fuel pattern, climate and weather. Landsc Ecol 21:121-137

Chew JD, Stalling C, Moeller K (2004) Integrating knowledge for simulating vegetation change at landscape scales. West J Appl Forestry 19:102-108

Collins M, Booth BBB, Harris GR, Murphy JM, Sexton DMH, Webb MJ (2006) Towards quantifying uncertainty in transient climate change. Clim Dyn 27:127-147

Colombaroli D, Henne PD, Kaltenrieder P, Gobet E, Tinner W (2010) Species responses to fire, climate and human impact at tree line in the Alps as evidenced by palaeo-environmental records and a dynamic simulation model. J Ecol 98:1346-1357

Cordonnier T, Courbaud B, Berger F, Franc A (2008) Permanence of resilience and protection efficiency in mountain Norway spruce forest stands: a simulation study. For Ecol Manag 256:347-354

Deutschman DH, Levin SA, Pacala SW (1999) Error propagation in a forest succession model: the role of fine-scale heterogeneity in light. Ecology 80:1927-1943

Elkin C, Reineking B, Bigler C, Bugmann H (2012) Do smallgrain processes matter for landscape scale questions? Sensitivity of a forest landscape model to the formulation of tree growth rate. Landsc Ecol 27:697-711

Elmqvist T, Folke C, Nyström M, Peterson G, Bengtsson J, Walker B, Norberg J (2003) Response diversity, ecosystem change, and resilience. Front Ecol Environ 1:488-494

Fahrig L (2003) Effects of habitat fragmentation on biodiversity. Annu Rev Ecol Evol Syst 34:487-515

Fischer J, Lindenmayer DB, Manning AD (2006) Biodiversity, ecosystem function, and resilience: ten guiding principles for commodity production landscapes. Front Ecol Environ 4:80-86

Hanewinkel M, Hummel S, Cullmann DA (2010) Modelling and economic evaluation of forest biome shifts under climate change in Southwest Germany. For Ecol Manage 259:710-719

He HS, Mladenoff DJ (1999) Spatially explicit and stochastic simulation of forest-landscape fire disturbance and succession. Ecology 80:81-99

Heinimann HR (2010) A concept in adaptive ecosystem management - an engineering perspective. For Ecol Manag 259:848-856

Henne PD, Elkin CM, Reineking B, Bugmann H, Tinner T (2011) Did soil development limit spruce (Picea abies) expansion in the Central Alps during the Holocene? Testing a palaeobotanical hypothesis with a dynamic landscape model. J Biogeogr 38:933-949

Hernández-Stefanoni J, Dupuy J, Tun-Dzul F, May-Pat F (2011) Influence of landscape structure and stand age on species density and biomass of a tropical dry forest across spatial scales. Landsc Ecol 26:355-370 
IPCC (2007) Contribution of working group II to the fourth assessment report of the intergovernmental panel on climate change. Climate change 2007: impacts, adaptation and vulnerability. Cambridge University Press, Cambridge

Jost L (2007) Partitioning diversity into independent alpha and beta components. Ecology 88:2427-2439

Keane RE, Morgan P, White JD (1999) Temporal patterns of ecosystem processes on simulated landscapes in Glacier National Park, Montana, USA. Landsc Ecol 14:311-329

Kennedy RSH, Wimberly MC (2009) Historical fire and vegetation dynamics in dry forests of the interior Pacific Northwest, USA, and relationships to Northern Spotted Owl (Strix occidentalis caurina) habitat conservation. For Ecol Manage 258:554-566

Kirilenko AP, Sedjo RA (2007) Climate change impacts on forestry. PNAS 104:19697-19702

Lasch P, Lindner M, Erhard M, Suckow F, Wenzel A (2002) Regional impact assessment on forest structure and functions under climate change-the Brandenburg case study. For Ecol Manag 162:73-86

Liang Y, He H, Bu R, Hu YM, Shao GF (2011) Are plot data effective for landscape prediction? A simulation study of tree species response to climate warming under varying environmental heterogeneity. Ann For Sci 68:899-909

McElhinny C, Gibbons P, Brack C, Bauhus J (2005) Forest and woodland stand structural complexity: its definition and measurement. For Ecol Manag 218:1-24

Miehle P, Livesley SJ, Li C, Arndt SK (2006) Quantifying uncertainty from large-scale model predictions of forest carbon dynamics. Glob Change Biol 12:1421-1434

MLR (1999) Richtlinie Landesweiter Waldentwicklungstypen. Ministerium Ländlicher Raum Baden-Württemberg, Stuttgart

Müller T, Oberdorfer E, Philiippi G, Walter E (1992) Potentielle natürliche Vegetation und Naturräumliche Einheiten. Landesanstalt für Umweltschutz Baden-Württemberg, Karlsruhe

Nothdurft A, Wolf T, Ringeler A, Böhner J, Saborowski J (2012) Spatio-temporal prediction of site index based on forest inventories and climate change scenarios. For Ecol Manag 279:97-111

Paillet Y, Bergès L, Hjältén J, Odor P, Avon C, BernhardtRömermann M, Bijlsma RJ, De Bruyn L, Fuhr M, Grandin U, Kanka R, Lundin L, Luque S, Magura T, Matesanz S, Mészáros I, Sebastià MT, Schmidt W, Standovár T, Tóthmérész B, Uotila A, Valladares F, Vellak K, Virtanen R (2010) Biodiversity differences between managed and unmanaged forests: meta-analysis of species richness in Europe. Conserv Biol 24:101-112

Papaik MJ, Fall A, Sturtevant B, Kneeshaw D, Messier C, Fortin M-J, Simon M (2010) Forest processes from stands to landscapes: exploring model forecast uncertainties using cross-scale model comparison. Can J For Res 40:23452359

Pretzsch H, Grote R, Reineking B, Rötzer T, Seifert S (2008) Models for forest ecosystem management: a European perspective. Ann Bot 101:1065-1087

Radeloff VC, Mladenoff DJ, Gustafson EJ, Scheller RM, He HS, Zollner PA, Akçakaya R (2006) Modeling forest harvesting effects on landscape pattern in the Northwest Wisconsin Pine Barrens. For Ecol Manag 236:113-126
Ravenscroft C, Scheller RM, Mladenoff DJ, White MA (2010) Forest restoration in a mixed-ownership landscape under climate change. Ecol Appl 20:327-346

Schlyter P, Stjernquist I, Brring L, Jönsson AM, Nilsson C (2006) Assessment of the impacts of climate change and weather extremes on boreal forests in northern Europe, focusing on Norway spruce. Clim Res 31:75-84

Schumacher S, Bugmann H (2006) The relative importance of climatic effects, wildfires and management for future forest landscape dynamics in the Swiss Alps. Global Change Biol 12:1435-1450

Schumacher S, Bugmann H, Mladenoff D (2004) Improving the formulation of tree growth and succession in a spatially explicit landscape model. Ecol Model 180:175-194

Schumacher S, Reineking B, Sibold J, Bugmann H (2006) Modeling the impact of climate and vegetation on fire regimes in mountain landscapes. Landsc Ecol 21:539-554

Seidl R, Rammer W, Jäger D, Currie WS, Lexer MJ (2007) Assessing trade-offs between carbon sequestration and timber production within a framework of multi-purpose forestry in Austria. For Ecol Manag 248:64-79

Seidl R, Fernandes PM, Fonseca TF, Gillet F, Jönsson AM, Merganicová K, Netherer S, Arpaci A, Bontemps J-D, Bugmann H, González-Olabarria JR, Lasch P, Meredieu C, Moreira F, Schelhaas M-J, Mohren F (2011) Modelling natural disturbances in forest ecosystems: a review. Ecol Model 222:903-924

Shifley SR, Thompson FR, Dijak WD, Fan ZF (2008) Forecasting landscape-scale, cumulative effects of forest management on vegetation and wildlife habitat: a case study of issues, limitations, and opportunities. For Ecol Manag 254:474-483

Steenberg JWN, Duinker PN, Bush PG (2011) Exploring adaptation to climate change in the forests of central Nova Scotia, Canada. For Ecol Manag 262:2316-2327

Sturtevant BR, Miranda BR, Shinneman DJ, Gustafson EJ, Wolter PT (2012) Comparing modern and presettlement forest dynamics of a subboreal wilderness: does spruce budworm enhance fire risk? Ecol Appl 22:1278-1296

Syphard AD, Yang J, Franklin J, He HS, Keeley JE (2007) Calibrating a forest landscape model to simulate frequent fire in Mediterranean-type shrublands. Environ Model Softw 22:1641-1653

Temperli C, Bugmann H, Elkin C (2012) Adaptive management for competing forest goods and services under climate change. Ecol Appl 22:2065-2077

Thornton PE, Running SW, White MA (1997) Generating surfaces of daily meteorological variables over large regions of complex terrain. J Hydrol 190:214-251

Uriarte M, Canham CD, Thompson J, Zimmerman JK, Murphy L, Sabat AM, Fetcher N, Haines BL (2009) Natural disturbance and human land use as determinants of tropical forest dynamics: results from a forest simulator. Ecol Monogr 79:423-443

Waldron JD, Lafon CW, Coulson RN, Cairns DM, Tchakerian MD, Birt A, Klepzig KD (2007) Simulating the impacts of southern pine beetle and fire on the dynamics of xerophytic pine landscapes in the southern Appalachians. Appl Veg Sci 10:53-64

Xu C, He HS, Hu Y, Chang Y, Larsen DR, Li X, Bu R (2004) Assessing the effect of cell-level uncertainty on a forest 
landscape model simulation in northeastern China. Ecol Model 180:57-72

Xu C, He HS, Hu Y, Chang Y, Li X, Bu R (2005) Latin hypercube sampling and geostatistical modeling of spatial uncertainty in a spatially explicit forest landscape model simulation. Ecol Model 185:255-269

Xu C, Gertner GZ, Scheller RM (2009) Uncertainties in the response of a forest landscape to global climatic change. Glob Change Biol 15:116-131
Yousefpour R, Temperli C, Elkin C, Bugmann H, Hanewinkel M, Meilby H, Bredahl Jacobsen J, Jellesmark Thorsen B (2012) Updating beliefs and combining evidence in adaptive forest management under climate change: a case study of Norway spruce (Picea abies L. Karst) in the Black Forest, Germany. Journal of Environmental Management (accepted) 